\title{
A FUNÇÃO SOCIAL DA EMPRESA, A RESPONSABILIDADE SOCIAL E A SUSTENTABILIDADE SOB A LUZ DOS FATORES ESG: ENVIRONMENTAL, SOCIAL AND GOVERNANCE
}

\section{ARTIGO ORIGINAL}

OLIVEIRA, Rosa Malena Gehlen Peixoto de ${ }^{1}$

OLIVEIRA, Rosa Malena Gehlen Peixoto de. A função social da empresa, a responsabilidade social e a sustentabilidade sob a luz dos fatores ESG: Environmental, Social and Governance. Revista Científica Multidisciplinar Núcleo do Conhecimento. Ano. 06, Ed. 12, Vol. 06, pp. 69-96. Dezembro de 2021. ISSN: 2448-0959, Link de acesso: https://www.nucleodoconhecimento.com.br/lei/a-funcaosocial

\section{RESUMO}

A partir da iniciativa da Organização das Nações Unidas (ONU), da qual resultou o Relatório Who Cares Wins, em 2004, no contexto do Pacto Global, exsurge o acrônimo $E S G$, que expressa uma ideia pela qual se propõe às corporações privadas a integrar os fatores environmental (meio ambiente), social (social) and governance (governança) como elementos indissociáveis do exercício da atividade empresarial, de modo a desenvolver uma cultura voltada a um propósito para além do lucro, num contexto de plena simbiose com os direitos humanos. Nessa perspectiva, mediante uma pesquisa bibliográfica e exploratória, buscar-se-á compreender o que é o ESG e os fatores que o integram, qual é a sua importância e os reflexos para as empresas da atualidade e do futuro, concluindo-se, ao final, tratar-se de um indeclinável imperativo contemporâneo que encontra na função social da empresa, na responsabilidade social e na sustentabilidade vetores conjugados que externalizam a

\footnotetext{
1 Pós-graduada em Direito Aplicado, pela Escola da Magistratura do Paraná. Pósgraduada em Direito Processual Civil, pela Pontifícia Universidade Católica do Paraná. Pós-graduanda em Direito Empresarial pelo UNICURITIBA.
} 
partir da adoção de uma gestão ética e comprometida, a geração de valor não apenas em proveito das partes interessadas, mas como um meio de construção de um mundo melhor.

Palavras-chave: Função social da empresa, responsabilidade social empresarial, sustentabilidade, ESG.

\section{INTRODUÇÃO}

Ainda no séc. III a.C, Aristóteles sustentava que o homem era um ser social e apenas poderia alcançar a felicidade vivendo em comunidade. (RAMOS, 2014, p. 64-65).

Muitas foram as fases vivenciadas pela humanidade ao longo da sua história. Ultrapassada a fase do período antigo e medieval, notadamente marcados pela subserviência a autocratas, durante o Estado Liberal no século XVIII o homem foi elevado ao epicentro das relações humanas (TAVARES, 2002, p. 359-360) razão pela qual em meados da época moderna tornaram-se proeminentes os conceitos de indivíduo e patrimônio (LENZA, 2015, p. 1489; TAVARES, 2002, p. 453).

Contudo, a liberdade outrora duramente conquistada mostrou-se insuficiente para thes garantir outros direitos de igual importância, porquanto desigualdades foram sendo reveladas e consequências nefastas amargadas, de modo que o Estado Liberal sucumbiu diante das demandas sociais que abalaram o século XIX. (NOVELINO, 2017, p. 56)

A liberdade, por si só, não confirmou a felicidade do homem. Era preciso mais, era preciso que ela se concretizasse no seio de uma sociedade, compartilhada entre seus integrantes, como séculos antes percebeu sabidamente Aristóteles.

Com o advento do Estado Social, no início do século XX, a igualdade passou a ser a temática a ser implementada, a fim de corrigir as distorções que a liberdade ilimitada e o abstencionismo integral do Estado provocaram. (LENZA, 2015, p. 1143; NOVELINO, 2017, p. 57). 
Nessa ambiência, a propriedade inicialmente como um direito puramente da esfera individual do homem recebeu uma função social a cumprir, tocando-lhe deveres para com os demais (BERNARDES; FERREIRA, 2018, p. 150).

Todas as Constituições da República do Brasil tutelaram o direito à propriedade como um direito subjetivo, mas foi a Constituição de 1988, assim como a sua antecessora, de 1967, com a redação conferida pela Emenda Constitucional no 01 de 1969, que a função social da propriedade emergiu como um princípio da ordem econômica (BRASIL, 1988; 1969).

Assim, por um lado, o direito de propriedade permanece fundamental como um direito de ordem subjetiva a todos deferido, como preceitua o art. 5ํ, inc. XXII, do texto constitucional, por outro figura como princípio que norteia a ordem econômica, nos termos do art. 170, inc. II, mas sob estas duas vertentes deverão atender a sua função social, ex vi do art. 5을. inc. XXIII e 170, inc. III. (BRASIL, 1988).

Nesta perspectiva e como decorrência da função social da propriedade, à empresa imputa-se igual desiderato (CRUZ, 2021, p. 84) razão pela qual a adoção de mecanismos eficazes de gestão empresarial espelha a assunção deste dever, revela seu compromisso com a sociedade, atribui-Ihe conformação constitucional, além de, especialmente e inegavelmente, contribuir para o bem comum.

Com efeito e não por outra razão, o Constituinte em 1988 determinou expressamente, também como princípio da ordem econômica, a defesa do meio ambiente, a defesa do consumidor, a redução das desigualdades, a busca do pleno emprego, entre outros, fundamentando a ordem econômica na valorização do trabalho humano e na livre iniciativa, a fim de assegurar a existência digna de todos conforme os ditames da justiça social. (BRASIL, 1988).

Evidenciar-se-á, nessa ambiência, a crescente expansão de uma cultura empresarial voltada ao atendimento de um propósito de existir para além do lucro, razão pela qual, a cada novo dia, especialmente motivado pela pandemia da Covid-19 (SMITH, 2021), maior é o engajamento de empresas que reconhecem e assumem a responsabilidade 
de uma atuação comprometida e, sobretudo, ética, porquanto evidenciam as vantagens competitivas que daí decorrerem, entrelaçando-se com a ideia de um capitalismo mais consciente e humano.

O objetivo deste artigo é compreender a função social da empresa, a assunção da responsabilidade social corporativa e a prática da sustentabilidade como elementos integrados ao ESG, expressão cunhada pela Organização das Nações Unidas (ONU), no contexto do Pacto Global, em 2004, a indicar na atualidade a inafastabilidade entre as estratégias empresariais adotadas e o Environmental (meio ambiente), o Social (social) e a Governance (governança), como expressão de uma cultura corporativa que acarreta longevidade institucional, sendo a atividade empresarial exercida num contexto de plena simbiose em prol dos direitos humanos, a se evidenciar a melhor fase porvir da humanidade, naquela na qual a fraternidade[2] se descortinará.

\section{DA FUNÇÃO SOCIAL DA EMPRESA, DA RESPONSABILIDADE SOCIAL EMPRESARIAL E A SUSTENTABILIDADE, MAS O QUE SERÁ O ESG NOS DIAS ATUAIS?}

O conceito de propriedade sempre foi inerente ao homem, em que pese ter se transformado ao longo da sua história.

Segundo narra o ilustre professor André Ramos Tavares (2002, p. 450-451), no período antigo, tem-se que os babilônios e os hebreus protegiam severamente a propriedade individual e, entre os gregos e romanos, que inicialmente apregoavam a propriedade comum, o conceito se transformou a partir do reconhecimento da família como instituição. No período medieval, ao seu turno, no qual o feudalismo era o regime adotado, a propriedade era direito de poucos, ao passo que na Idade Moderna, em razão do desbravamento de novas terras e com o triunfo do capitalismo, a propriedade ganhou especial relevo.

Mas é do conceito atribuído durante período contemporâneo que se deve compreender a propriedade. 
Como já referido, o conceito de propriedade na Idade Moderna passava pela ideia de que o homem, como indivíduo, era o epicentro das relações jurídicas, de forma que a propriedade orbitava a sua esfera individual com exclusividade, exercendo com liberdade irrestrita o direito que tinha sobre seus bens (LENZA, 2015, p. 1489; TAVARES, 2002, p. 453).

Em razão das consequências nefastas e da profunda desigualdade social, com o advento do movimento socialista, em contraponto ao movimento liberalista, a propriedade deixa de integrar somente o âmbito da existência do indivíduo, pois ele não é um ser isolado é, em verdade, um ser social e, assim, consequentemente a sua propriedade passa a ter a função de também servir aos demais. (FARIAS; ROSENVALD, 2018, p. 319).

No receituário liberal definia-se o direito subjetivo como o poder concedido pelo ordenamento ao indivíduo para a satisfação de seu interesse próprio (...) exaltava-se conduta egoística de contratantes e proprietários, pois a sociedade era mera ficção, já que a felicidade coletiva dependeria da concessão da ampla liberdade a qualquer cidadão para consecução de seus projetos pessoais. (...) a evolução social demonstrou que a justificação de um interesse privado muitas vezes é fator de sacrifício de interesses coletivos. Há muito, não mais se admite que a satisfação de um bem individual seja obtida "às custas da desgraça alheia". (FARIAS; ROSENVALD, 2018, p. 314-315)

Disso se extrai, portanto, que na época contemporânea vigora o princípio da função social da propriedade de modo que "fica o proprietário jungido a observar desde o papel produtivo que deve ser desempenhado pela propriedade - passando pelo respeito à ecologia - até o cumprimento da legislação social e trabalhista (...)". (ORRUTEA, 1998, apud TAVARES, 2002, p. 459)

A função social da empresa, como consectário, decorre diretamente da propriedade e da função social desta, pois se a empresa pode ser entendida como "atividade econômica organizada para a produção ou circulação de bens e ou de serviços", como sintetiza o art. 966, do Código Civil (BRASIL, 2002) significa que sob a sua regência tem-se um complexo de bens organizados, materiais ou imateriais, que viabilizam o exercício desta atividade (CRUZ, 2021, p. 170; 173), assim denominados de bens de produção, ou seja: 
Por bens de produção, como conceito jurídico, devem-se compreender todos os reunidos pelo empresário na organização do estabelecimento empresarial. Embora sobre estes bens, nem sempre o empresário exerce especificamente o direito de propriedade (entre eles, há os alugados, os alienados fiduciariamente, os objetos de leasing, etc), é fato que os controla e decide se serão, e como serão, empregados na exploração da atividade econômica. Essa decisão deve se orientar pelo atendimento da função social da empresa. (COELHO in SALOMÃO; CUEVA; FRAZÃ̃o, 2020, p. 448)

A Lei 6.404/1976, que é a Lei das Sociedades Anônimas, preconiza tanto no art. 116 parágrafo único, quanto no seu art. 154, que caberá à companhia o direito de realizar os seus fins, satisfeita a sua função social, de modo que o legislador reconhece um amplo papel a ser exercido pela empresa no âmbito de sua inserção.

Logo, costuma-se evidenciar que a empresa cumpre a sua função social quando:

(...) gera empregos, tributos e riquezas, contribui para 0 desenvolvimento econômico, social e cultural da comunidade em que atua, de sua região ou país, adota práticas empresariais sustentáveis visando à proteção do meio ambiente e respeita os direitos dos consumidores. (COELHO in SALOMÃO; CUEVA; FRAZÃO, 2020, p. 448)

O ilustre professor Fábio Konder Comparato (1996, p. 44-46) reconhece que há interesses internos e externos que devem ser levados em conta no exercício da atividade empresarial, apontando inexistir maiores dificuldade para compreensão dos deveres negativos, mas questiona os deveres positivos, de modo a não "servir como mero disfarce retórico para o abandono pelo Estado de toda política social", pois sustenta que:

A empresa capitalista - importa reconhecer - não é, em última análise, uma unidade de produção de bens ou de prestação de serviços, mas sim uma organização produtora de lucros. (...) No regime capitalista, o que se espera e exige delas é, apenas, a eficiência lucrativa (...) Mas é uma perigosa ilusão imaginar-se que, no desempenho dessa atividade econômica, o sistema empresarial, livre de todo o controle dos Poderes Públicos, suprirá naturalmente as carências sociais e evitará abusos; em suma, promoverá a justiça social.

De fato, não há como negar que a empresa visa ao lucro. Não é a função social da propriedade ou a função social da empresa, tampouco a função social dos contratos 
que motiva os sujeitos a criar vínculos jurídicos, mas a satisfação desses na consecução de seus interesses e na captação de benefícios que lhes são particulares.

O lucro é legítimo e necessário estímulo para dar concretude aos esforços empreendidos, no entanto, é igualmente preciso constatar que:

Com o processo de globalização, a empresa assume papel mais decisivo na ordem jurídica contemporânea. Se dela provém a grande maioria de bens e serviços consumidos, urge, em contrapartida, que a sua função social deva resultar de uma ampliação de sua responsabilidade social, redefinindo e valorizando a sua missão perante a coletividade. Essa contribuição social não importa diminuição de lucros, tampouco desoneração do Estado sobre as funções que lhe são inerentes. A empresa não pode renunciar à sua finalidade lucrativa, mas é tão responsável quanto o Poder Público em assegurar direitos fundamentais (...)". (FARIAS; ROSENVALD, 2018, p. 358)

Este é um contraponto que se faz entre as empresas narcisistas e as empresas filantrópicas, a se ver:

Os defensores da política liberal retiravam da empresa qualquer obrigação social, pois entendiam a organização como um ente impessoal e consequentemente, como tal, não possui sensibilidade própria do ser humano individualizado. O foco das atenções das corporações deve ser o livre mercado, num ambiente eficaz de competição. Os problemas sociais eram resolvidos pelo Estado. (...) Amartya Sem e Bernardo Kliksberg, referindo-se a esse período, dizem que era a época da "empresa narcisista". (...) No séc. XXI, a empresa filantrópica evoluiu. (...) Percebe-se uma maior conscientização da sociedade e da própria empresa no sentido de que os problemas sociais não são unicamente da responsabilidade do Estado. (BARACHO; CECATO, 2017, p. 122-123).

E atualmente as empresas são, de fato, uma força paralela ao Estado, pois a título de exemplo "segundo dados sistematizados pela Global Justice Now, a partir da comparação direta entre as receitas anuais das empresas e as receitas anuais dos países, dentre as 100 maiores economias mundiais, 69 eram empresas no ano de 2015" (SCABIN; ACCA, 2017, p. 14) o que confirma a importância e a expressividade que assumem no contexto mundial.

Não há dúvidas que são elas verdadeiras agentes de criação e de transformação da realidade. 
Frente a esta conjuntura, no ano de 2000, a Organização da Nações Unidas (ONU) ao lançar o Global Compact (Pacto Global) iniciou um processo de engajamento internacional, convocando o setor privado e suas respectivas corporações para se unirem as ações capitaneadas por Estados, organizações internacionais, sociedade civil, a fim de estabelecer uma rede na direção de reconhecer e, sobretudo, aplicar os direitos humanos no mundo corporativo, definindo, naquela oportunidade, dez princípios universais a partir das diretrizes cunhadas na Declaração dos Direitos Humanos; na Declaração da Organização Internacional do Trabalho sobre Princípios e Direitos Fundamentais no Trabalho; na Declaração do Rio sobre Meio Ambiente e Desenvolvimento e a Convenção das Nações Unidas contra a Corrupção. (PEREIRA; RODRIGUES in NOHARA; ALMEIDA, 2021, p. 101).

O Pacto Global não é um instrumento regulatório, um código de conduta obrigatório ou um fórum para policiar as políticas e práticas gerenciais. E uma iniciativa voluntária que fornece diretrizes para a promoção do crescimento sustentável e da cidadania, por meio de lideranças corporativas comprometidas e inovadoras. (REDE BRASIL DO PACTO GLOBAL, s.d)

Surgia a partir daqui a superação da ideia de que os problemas sociais e o meio ambiente eram preocupações exclusivamente estatais.

Alguns anos mais tarde, em 2004, uma publicação do Pacto Global em parceria com o Banco Mundial, denominada de Who Cares Wins - Connecting Financial Markets to a Changing World, resultado da convocação de 50 CEOs de grandes instituições financeiras mundiais, que visou a provocá-los a integrar os fatores sociais, ambientais e de governança na análise dos investimentos no mercado de capitais (o que ao final ajudaria a alavancar a aplicação dos princípios definidos pelo Pacto Global), propôsse o termo ESG, isto é, Environmental, Social and Governance (REDE BRASIL DO PACTO GLOBAL, s.d).

Importante mencionar, em retrospecto a tal fato, que já na década de 1980, as empresas começaram a perceber que ir além da legislação, adotando práticas socioambientais, como a prevenção da poluição, respeito aos trabalhadores e 
sociedade em geral, também era fonte de lucro (REDECKER; TRINDADE, 2021, p. $67)$.

Isso porque em 1972, realizou-se por iniciativa da Organização das Nações Unidas (ONU) a Conferência de Estocolmo, seguida da Convenção de Viena em 1985 e o Tratado de Montreal em 1987, ano este que foi emitido o Relatório Brundtland, da Comissão Mundial de Meio Ambiente e Desenvolvimento da ONU, conhecido como "Nosso Futuro Comum" (NAÇÕES UNIDAS NO BRASIL, 2020), e que trouxe o conceito de desenvolvimento sustentável[3] para o discurso público, incorporado no Brasil pela Lei 6.938/1981, notadamente nos seus artigos $2^{\circ}$ e $4^{\circ}$, inc. I, e posteriormente pela Constituição Federal de 1988, em seu art. 225.

Neste contexto a sustentabilidade:

(...) surge como uma palavra que serve para todo empreendimento, todo processo produtivo e toda solução para o século seguinte. A sustentabilidade do desenvolvimento surge do limite anunciado da racionalidade econômica, proclamando os valores da vida, da justiça social e do compromisso com as gerações vindouras! (LEFF, 2011, apud BARACHO; CECATTO, 2017, p. 123).

Foi preciso entender, em que pese ainda seja, que a sustentabilidade não era irreconciliável com o crescimento econômico da empresa, mas que, ao contrário, podia ser importante fonte de vantagem competitiva e de geração de valor para acionistas e comunidade em geral (HART; MILSTEIN, 2004, p. 66).

E, de fato:

As empresas, também na década de 90 , começaram a perceber que já havia um público disposto a pagar mais por produtos denominados verdes, de modo especial na Europa e nos EUA, em que a cultura e a condição econômica favorecem a tal tomada de decisão. (...) Trata-se da possibilidade de um novo mercado, no qual o consumo consciente começa a ser difundido. São sinais de que a relação entre o consumidor e a empresa passa por algum tipo de transformação. Os consumidores, mais exigentes, passam a demonstrar que os valores humanos, bem-estar social e preservação ambiental também estão sendo considerados no momento da compra de bens e serviços. (GARCIA et al., 2008. p. 75-76). 
Para além disso, tem-se em vigor a Declaração Universal dos Direitos Humanos (1948); a Convenção Internacional sobre a Eliminação de Todas as Formas de Discriminação Racial (1966); a Convenção da Organização Internacional do Trabalho (1989); e tantas outras no reconhecimento, basicamente, das diversidades sociais e da interesecção da vida do homem e natureza, contemplando os direitos humanos, sob as óticas da primeira, segunda e terceira dimensão[4].

Neste diapasão, se por um lado a sustentabilidade primeiramente identificou-se com a preservação do meio ambiente a fim de assegurar um solidariedade intergeracional é importante referenciar o conceito de responsabilidade social, surgido por volta de 1950, cuja origem está assentada às questões éticas que envolviam a relação entre empresas e sociedade, mediante ações filantrópicas voltadas compensar os impactos negativos da atuação daquelas. (BORGER, 2013).

$\mathrm{Na}$ atualidade, este conceito é mais amplo, de forma que responsabilidade social:

(...) consiste um conjunto de iniciativas por meio das quais as empresas buscam - voluntariamente - integrar considerações de natureza ética, social e ambiental às suas interações com clientes, colaboradores, fornecedores, concorrentes, acionistas, governos e comunidades - as chamadas "partes interessadas" - visando ao desenvolvimento de negócios sustentáveis. (CONFEDERAÇÃO NACIONAL DA INDÚSTRIA, 2006, p. 9)

Segundo explica o Instituto Ethos (2003, p. 13) a responsabilidade social empresarial está "além do que a empresa deve fazer por obrigação legal. (...) Incorporar critérios (...) na gestão estratégica do negócio e traduzir as políticas de inclusão social e de promoção da qualidade ambiental, entre outras" reflete o reconhecimento desta responsabilidade.

Percebe-se, em verdade, que "o conceito de desenvolvimento sustentável está hoje totalmente integrado ao conceito de responsabilidade social: não haverá crescimento econômico em longo prazo sem progresso social e também sem cuidado ambiental." (BORGER, 2013). 
Nesta perspectiva, é importante constatar que os conceitos de função social da empresa, de sustentabilidade e de responsabilidade social representam, juntos, "um conceito ético que envolve mudanças nas condições de bem-estar e está ligada às dimensões sociais das atividades produtivas e suas ligações com a qualidade de vida da sociedade" (PEREIRA; RODRIGUES, in NOHARA; ALMEIDA, 2021, p. 356) e que acabam redundando no mesmo objetivo.

É, portanto, a partir destes conceitos integrados que o exercício da atividade empresarial na atualidade deve se pautar, cuja ótica deve ser multifacetada, estruturando-se a partir da compreensão que "as instituições devem colaborar com todos aqueles sujeitos que de alguma forma são impactados pelas suas atividades" (REDECKER; TRINDADE, 2021, p. 71-72).

No regime jurídico interno, importante asseverar que a Constituição Federal de 1988, que adotou o Estado Democrático de Direito e que "representa um novo paradigma em face do qual os princípios constitucionais e os direitos fundamentais são contextualizados e recebem uma nova leitura" (FRAZÃO, in SALOMÃO; CUEVA e FRAZÃO (coords), 2020. p. 105), incorporou os direitos fundamentais, a sustentabilidade ambiental, a função social da propriedade e da empresa, a responsabilidade social, razão pela qual a ordem jurídica constitucional brasileira ao passo que garante o desenvolvimento, valorizando a livre iniciativa, ordena o bem de todos.

Nessa ambiência é possível afirmar que o modelo econômico constitucionalmente adotado pelo Brasil amolda-se ao hoje denominado capitalismo consciente, no qual todas as conclusões acerca da função social, responsabilidade social e sustentabilidade, ao final, parecem repousar pois:

O conceito foi apresentado na década passada, propondo um modelo de funcionamento no qual o lucro não é o objetivo fundamental das empresas. Esta nova conceção de capitalismo sustenta-se na ideia de que o lucro é consequência de uma ação orientada para um propósito maior. Este propósito justifica a existência de empresas vinculadas à geração de valor para todas as partes envolvidas no processo de produção e comercialização, inscrevendo-se, assim, no compromisso de construção de um mundo melhor. (LIMA; RIBEIRO, 2020, p. 2) 
Segundo o Instituto Brasileiro de Governança Corporativa externalizou (IBGC, 2020):

O notável avanço das preocupações de investidores, empresas, governos e indivíduos com questões climáticas e sociais tem consolidado o fim da chamada "doutrina Friedman", segundo a qual o propósito primordial das empresas é a geração de lucros para os acionistas. Nessa segunda década do século 21, essa visão está superada e dá lugar à percepção de que esse sistema deu muito errado. É nesse contexto que ganham cada vez mais espaço os fatores ESG (ambientais, sociais e de governança).

É justamente da ideia de um capitalismo mais consciente em relação às questões socioambientais que emergiu o conceito do investimento socioambiental responsável, cuja estreia deu-se em 1999 pelo índice Dow Jones de Sustentabilidade, pelo qual se passou a aferir o desempenho financeiro das empresas que incorporavam critérios éticos em seu modelo de negócio. (REDECKER; TRINDADE, 2021, p. 68)

O relatório da Organização das Nações Unidas (ONU), referente ao Pacto Global, em parceria com o Banco Mundial, Who Cares Wins[5] (INTERNACIONAL FINANCE CORPORATION, 2004, p. 5, tradução nossa) mencionou, nesta ambiência, que:

As instituições que endossam este relatório estão convencidas de que em um mundo mais globalizado, interconectado e competitivo, a maneira como as questões ambientais, sociais e de governança corporativa são gerenciadas faz parte da qualidade geral da gestão das empresas, necessária para competir com sucesso.

Segundo a B3 (2016, p. 9):

Os índices de sustentablidade, os fundos de investimento atrelados a tais índices (exchange-tradded funds), os seguementos especiais de listagem em bolsa de valores e as agências de pesquisa e rating especializada em temas ESG tiveram crescimento exponencial nos últimos anos.

Isso porque conforme a própria a B3 $(2016$, p. 7) explica as empresas que são sustentáveis inovam, pois identificam novas oportunidades de negócios; fidelizam consumidores, gerando mais receitas; otimizam seus custos, com a redução de uso de água, energia e outros insumos; mitigam riscos ambientais, operacionais, de mercado e financeiros e, por fim, melhoram sua reputação e imagem. 
Um dos motivos é a melhor competitividade, porque o consumidor, como já mencionado, está mais atento às práticas adotadas pelas empresas, a exemplo de um levantamento realizado pelo Instituto Akatu e GlobeScan, em 27 países, e que revelou que no Brasil, "mais de $70 \%$ dos consumidores esperam que as empresas não agridam o meio ambiente e mais de $60 \%$ querem que as empresas estabeleçam metas para tornar o mundo melhor". (GUIMARÃES, 2021).

Disso se extrai uma consequência prática positiva, pois empresas responsáveis, que praticam o capitalismo consciente, estão tendo maior lucratividade de modo mais sustentado, isto é:

As organizações conscientes também se empenham em obter desempenho financeiro excepcional no longo prazo. Uma amostra representativa delas, por exemplo, superou o mercado global de ações (em uma relação de 10,5:1) em um período de 15 anos, oferecendo mais de $1600 \%$ de retorno total, enquanto a média de mercado no mesmo período foi de pouco mais de 150\% (MACKEY e SISODIA, 2013, p. 72 apud LIMA; RIBEIRO, 2020, p .6)

Outrossim, outra recente pesquisa realizada pela Humanizadas do Brasil, divulgada pelo Movimento Capitalismo Consciente Brasil, sustenta que:

Confirmando a teoria capitalista consciente, aponta que a rentabilidade (ROE em \% acumulada de 2000 a 2019) das empresas humanizadas da amostra é 3,5 vezes superior a das 500 maiores empresas do Brasil. Também ficou evidente a correlação entre a performance ESG das companhias pesquisadas e seu rating de consciência organizacional (medido pelo grau de qualidade da relação com clientes, fornecedores, colaboradores, acionistas e sociedade em geral). (NETO; FUKAYAMA, 2021)

E, de fato, um estudo realizado pela Global Reporting Initiative (2019, p. 4; 12) constatou, em escala global, uma forte pressão dos investidores e demais partes envolvidas sobre os Conselhos de Administração para que atentem para as exigências do mercado acerca dos fatores ESG, concluindo-se que todas as evidências indicam os impactos positivos nos resultados das empresas, como benefícios comerciais e vantagens competitivas quando há integração destes fatores.

Isso muito porque como já se evidenciava há mais de uma década: 
(...) os consumidores estão demandando mais das organizações do que simplesmente qualidade do produto e preços baixos; eles esperam que a organização demonstre congruência com alguns valores sociais como contribuição para a sociedade. (GARCIA et al., 2008, p. 81)

Logo, a conclusão do enredo ESG é que a sociedade na atualidade espera e exige que as empresas atuem de forma adequada ao bem comum, de maneira que "nas últimas décadas, essa expectativa é cada vez mais presente, assim como a exigência que as empresas adotem cada vez mais um comportamento condizente com as práticas que não tragam impactos sociais e ambientais negativos". (SCABIN; ACCA, 2017, p. 14)

Diante disto, as empresas devem se atentar, pois "o apetite por investimentos sustentáveis só aumentou nos últimos anos: $54 \%$ dos babies boomers tendem a optar por este tipo de investimento, representatividade que sobe para $78 \%$ nos millenials e 84\% na geração Z". (PEREIRA, 2020).

A humanidade, mais informada do que nunca, está mudando, razão pela qual "na era da hipertransparência e hiperconectividade não é opção ficar alheio às demandas da sociedade" (PEREIRA, 2020).

Assim, retomando-se o proposto pelo Pacto Global lá em 2000 e refletindo acerca do ESG como sugerido em 2004, malgrado inicialmente vinculado à análise do setor de investimentos, sem dúvida é certo afirmar que ele contempla e incorpora a função social da empresa, o modelo da sustentabilidade e a responsabilidade social, mas é, como constatação, também um convite para que se compreenda o propósito existencial das corporações para além do lucro num mundo, conquanto interconectado e globalizado, vulnerável, eis que segundo Colin Meyer, professor de estudos de gestão na Saïd Business School, da Universidade de Oxford, a questão que surge agora é "por que as empresas existem?" (IBGC, 2020).

Neste século, não se tolera a ideia de que direitos humanos, sob quaisquer perspectivas e em qualquer profundidade, sejam violados. É preciso incluir e cuidar do outro (combater trabalho análogo a escravo e o trabalho infantil, qualquer tipo de 
discriminação em relação à mulher, à raça, à opção sexual); zelar pela comunidade próxima e preservar o meio ambiente.

Como cita Jim Collins (2018, p. 256) ao analisar um conjunto de empresas que passaram de boas a excelentes mantendo sua longevidade, é reconhecer um conjunto de valores centrais firmemente estabelecido que identifica a empresa muito mais do que qualquer dos seus produtos, a incluir inovações técnicas, respeito aos indivíduos, responsabilidade perante a comunidade em que está inserida e ter como inequívoco a "firme convicção que o lucro não é a meta fundamental da empresa."

Pensando nisso, o Departamento de Inovação Social do CAF - Banco de Desenvolvimento da América Latina tem se empenhado em promover um novo paradigma, que redefine o sentido do sucesso nos negócios, reformulando uma pergunta básica: qual é o propósito da empresa na sociedade? Ao responder a essa pergunta, o retorno financeiro passa a ser entendido como uma ferramenta indispensável para atingir seus objetivos, mas não como a sua única razão de existir. O sucesso é medido, então, não apenas pelo seu nível de faturamento, lucros ou dividendos, mas também como seu modelo de negócios integra os benefícios com o impacto na sociedade e no meio ambiente de forma mensurável e escalável. (CORREA, 2019, p. 1213).

Neste panorama, as empresas devem emergir definitivamente nos fatores ESG, cuja desenvoltura se dá com base na era do propósito e do capitalismo mais consciente, o que se inclui perfeitamente no Estado Democrático de Direito adotado pelo Brasil desde a Constituição Federal de 1988, de forma a unir axiologicamente tanto as ações do Estado, quanto as práticas do setor privado, além da própria sociedade.

Como lecionam Redecker e Trindade (2021, p. 78): "Todos os fundamentos constitucionais elencados sustentam a premissa ESG".

Posto isto, sintetize-se a ideia de que o ESG (Environmental, Social and Governance) ou ASG (Ambiental, Social e Governança), "(...) em sentido amplo, é uma filosofia de gestão, que leva em consideração fatores além do lucro, como ética, governança corporativa e responsabilidade socioambiental". (MORSH, 2021).

Portanto, tem-se uma modificação de paradigma, pois: 
No século $X X I$, os intangíveis podem ser mais valiosos do que os ativos tangíveis. Tem-se, então, o chamado "efeito iceberg", onde os aspectos tangíveis são contabilizados e o que é realmente valioso não é visto no balanço patrimonial nem na demonstração dos resultados. Intangíveis, como goodwill, marca, reputação, qualidade da governança, qualidade da gestão, histórico de respeito aos direitos humanos, aspectos sociais e trabalhistas e a consideração dos ecossistemas na comunidade onde a empresa opera, tornaram-se temas relevantes. (IBGC, 2007, p. 6)

O ESG, nessa perspectiva, não é um feixe da atuação corporativa limitada a uma área ou departamento, é preciso que permeie toda a organização integrando todo processo decisório e toda a cadeia, de forma a permitir a identificação da corporação e de sua missão, porquanto:

\begin{abstract}
Sabemos que investidores, cada vez mais, preocupam-se em direcionar seus investimentos a companhias com práticas ESG, mas não só. Consumidores, e não só mais jovens, também revelam uma forte tendência em investir, consumir ou até mesmo trabalhar em empresas sustentáveis. É a busca pelo propósito, um olhar mais humano e consciente. Todas as partes interessadas estão mais atentas e exigentes em relação a uma maior performance socioambiental e de governança e, ainda, atrelada a melhores resultados financeiros. (REDE BRASIL DO PACTO GLOBAL; STILINGUE, 2021, p. 4)
\end{abstract}

Considerando-se, assim, todos estes indicadores, notadamente os índices de rentabilidade das empresas alinhadas ao ESG, as tendências de mercado ditadas pelos consumidores, o comportamento dos mais jovens, além das regulamentações estatais conectadas com os fatores ESG, entre outros aspectos, a tendência é que as pressões pela adoção das respetivas práticas sejam cada vez maiores nos próximos anos (GLOBAL REPORTING INICIATIVE, 2019, p. 5).

Afinal:

(...) todos podemos ser atores na construção da sociedade em que queremos viver: em cada uma de nossas decisões econômicas temos a oportunidade e o privilégio de decidir como comprar e o que consumir, podemos oferecer empregos nos quais as pessoas encontrem significado e orgulho e não apenas salário, podemos ensinar que o mercado pode ser uma plataforma de encontro - onde os cidadãos podem agir alinhados com seus valores - e não apenas um espaço para trocar mercadorias por dinheiro. Podemos mudar para que o modo comum de fazer negócios seja resolver os problemas do 
mundo, para que os mercados possam oferecer as soluções em escala que os desafios do século XXI exigem. (CORREA, 2019, p. 175).

Para finalizar, uma última ressalva que se faz acerca do ESG, supostamente já percebida, é a seguinte:

(...) muito cuidado para quem quer implementar o ESG, pois não basta criar um produto ou uma linha de produtos mais verdes, sustentáveis ou somente apoiar um projeto social. Estamos é falando aqui de gestão, governança, controles e avaliações. É inserir as questões ambientais e sociais no cerne da estratégia dos negócios e em todos os processos. (NAKAGAWA, 2020)

Portanto, além do reconhecimento da função social da empresa e assunção de uma responsabilidade socioambiental, o ESG visa a conectar a missão da empresa a uma ideologia organizacional que busca alinhar suas estratégias com o bem comum, caminho pelo qual obterá sucesso estratégico, perenidade e empoderamento no meio em que se desenvolve.

\section{DECIFRANDO O ACRÔNIMO ESG: ENVIRONMENTAL, SOCIAL AND GOVERNANCE}

Mostra-se relevante conceituar cada uma das facetas do ESG: E (Environmental); S (Social) e o G (Governance) para melhor compreendê-lo.

Primeiramente é preciso dizer que a ética é o ponto de partida, entendendo-se que:

Temos, portanto, que esclarecer o que queremos dizer quando falamos em ética. $E$, para isso, devemos fazer uma distinção entre os conceitos de ética e moral. (...) A moral é definida como conjunto de valores, de princípios, de regras que norteiam o comportamento humano. No espaço da moralidade, aprovamos ou reprovamos o comportamento dos indivíduos e o designamos como certo ou errado, correto ou incorreto. Há sempre uma expectativa da sociedade em relação ao desempenho dos papéis e nossa conduta é aceita ou rejeitada à medida que corresponda ou não a essa expectativa. A ética é a reflexão crítica sobre a moralidade. Não tem a pretensão de definir normas, mas indicar princípios. Quando fazemos uma reflexão ética, estamos nos perguntando sobre a consistência e a coerência dos valores que norteiam nossas ações de caráter moral (...). (RIOS, 2008, p. 84) 
A ética é, como sugere a breve análise acima, uma reflexão crítica do ser sobre o conjunto de valores que norteia os comportamentos e indica modos de agir. A mesma concepção, na atualidade, é aplicável às empresas, de forma que:

uma deliberação ética é aquela que considera, em todo o processo de tomada de decisão, tanto a identidade da organização quanto os impactos das decisões sobre o conjunto das partes interessadas, a sociedade em geral e o meio ambiente, visando ao bem comum" (IBGC, 2015, p. 17).

Em segundo lugar, importante noticiar que o ESG não se confunde com compliance, pois, conforme o Instituto Brasileiro de Governança Corporativa explica este "deve ser entendido como um conjunto de processos interdependentes que contribuem para a efetividade do sistema de governança e que permeia a organização, norteando as iniciativas e ações dos agentes de governança no desempenho de suas funções". (IBGC, 2017, p. 11).

Portanto, "o compliance é parte do ESG, mas não é tudo. (...) A boa governança corporativa e a gestão de riscos do negócio também fazem parte do pilar G. (...) ESG é mais amplo e estratégico." (LEGAL ETHICS COMPLIANCE, 2021).

O compliance está a serviço do ESG, sendo neste abrangidos os "conceitos de identidade organizacional", que é a "combinação entre seu propósito (razão de ser), sua missão, sua visão (aonde quer chegar), seus valores e seus princípios - o que é importante para ela". (IBGC, 2017, p.17).

Ademais, sustenta-se que ao revés de ESG ou ASG (no português):

(...) talvez a ordem das letras deveria ser diferente: afinal, é o "G" que garante o tecido que incorpora os outros dois pilares. Sem uma boa governança não é possível estruturar um modelo verdadeiramente sustentável. (IBGC, 2020).

Postas estas ligeiras observações e visando a decifrar o macrocosmo ESG, pode-se dizer que o $E$ (environmental) relaciona-se ao meio ambiente e com os recursos naturais utilizados pela empresa na sua atividade e vincula-se diretamente com o princípio do desenvolvimento sustentável, outrora mencionado. 
Uma vez incorporada essa cultura consciente da necessária contribuição com a manutenção do meio ambiente sadio para as presentes e futuras gerações, a empresa passa a tomar decisões vinculadas à ética ambiental, muitas vezes resolvendo desacordos da própria organização ou as existentes a sua volta. Este processo decisório inclui desde a fase de elaboração de um projeto até a eliminação dos resíduos, durante toda a vida útil (BATALHA, 2013, p. 5), a racionalidade no uso do transporte, no uso de embalagens, a promoção da educação ambiental (CONFEDERAÇÃO NACIONAL DA INDÚSTRIA, 2006, p. 28), entre outros.

Note-se:

(...) dentre as possíveis ações para a manutenção de uma gestão ambiental responsável, destaca-se: (i) a implementação de um sistema de gestão ambiental; (ii) a realização do processo produtivo, substituindo produtos tóxicos ou nocivos por outros de menos prejudiciais; (iii) a elaboração de códigos de conduta de respeito ao meio ambiente; (iv) a diminuição do consumo de matérias primas, água e energia. (REDECKER; TRINDADE, 2021, p. 86).

Um exemplo nacional, que pode ser destacado pela inexistência de critérios associados ao ESG na tomada de decisões é a tragédia de Mariana (a qual veio a se repetir em Brumadinho), pois o que se constatou foram graves problemas de gestão antes, durante e depois dos desastres, a ausência de prévios e completos estudos do impacto ambiental; falta de transparência da informação das causas que motivaram a localização da barragem, entre outras (PEREIRA; RODRIGUES in NOHARA; ALMEIDA, 2021, p. 313-315).

Além dos fatores sociais, como a perda de 19 vidas, 41 cidades afetadas em Minas Gerais e Espírito Santo e 3 reservas indígenas prejudicadas, o desastre de Mariana acarretou o derramamento de mais de 50 milhões de metros cúbicos de rejeitos de mineração em terrenos e rios acarretando poluição hídrica, a devastação de vegetação e animais, a destruição de 240,88 hectares de mata atlântica, a mortandade de 14 toneladas de peixes, além da alteração de ecossistemas, sendo considerado um dos maiores desastres registrados no mundo com consequências imediatas e futuras. (MINISTÉRIO PÚBLICO FEDERAL, s.d). 
É preciso ter em mente que o meio ambiente é promovedor da qualidade da vida humana e igualmente garantidor da própria existência e é bem verdade que não há como negar que:

Os impactos da atividade humana sobre o meio ambiente são significativos e vem alterando o clima e os ecossistemas do planeta. Os relatórios do IPCC - Painel Intergovernamental sobre Mudanças Climáticas, que reúne algumas das principais comunidades científicas acerca do tema - analisam a evolução de indicadores como temperatura dos oceanos, nível de degelo da região dos polos terrestres, concentração de gás carbônico e outros gases causadores do efeito estufa na atmosfera, entre muitos outros. Esses indicadores mostram como a evolução da atividade econômica e industrial está associada a mudanças significativas no clima em escala global. (IEDE, 2021, p. 6).

No processo decisório ambiental ético, portanto, é importante estabelecer critérios adotando-se alternativas tecnológicas que mitiguem riscos ambientais; que a escolha se dê pela energia limpa; que a definição de implantação de unidades fabris seja criteriosa (PEREIRA; RODRIGUES in NOHARA; ALMEIDA, 2021, p. 311), porque relembre-se, agora, o lucro não é o fator mais importante e, sim, as externalidades positivas e a mitigação, senão a eliminação, das negativas decorrentes da atividade empresarial.

Como muito bem pontuou com uma clareza solar Roberto Marques, Presidente do Conselho Executivo de Administração e CEO da Natura \& Co, numa entrevista concedida à Fundação Getúlio Vargas, "Não existe o plano B, só existe o plano A, que é fazer isso dar certo, porque o mundo não tem volta (...) atuar com senso de urgência (...) porque não se conseguirá gerenciar negócios num planeta destruído". (FUNDAÇÃO GETÚLIO VARGAS, 2021).

É com base nesta visão holística sobre a questão, a título exemplificativo, que a Natura \& Co estabeleceu 31 objetivos a serem perseguidos dentro dos próximos anos que consiste, dentre as principais, "atingir zero em emissões líquidas de carbono (...) e implementar um modelo econômico circular, em que 100\% das embalagens usadas sejam reutilizáveis, recicláveis ou compostáveis." (WEBER, 2021). 
Já no tocante ao S (Social) pode-se entender a vinculação da empresa com os terceiros:

\begin{abstract}
O S passou a ser desenvolvido a partir de uma atuação que busca (i) assegurar a igualdade e respeito pelos Direitos Humanos a todos os indivíduos da sociedade, (ii) promover uma sociedade justa com inclusão social e foco na extinção da pobreza; (iii) evitar qualquer forma de exploração humana; (iv) procurar o bem da comunidade em geral. (REDECKER; TRINDADE, 2021, p. 88).
\end{abstract}

A tomada de decisão ética, neste caso, em relação aos empregados seria exemplificativamente "igualdade de oportunidades (sexo, etnia, idade, necessidades especiais); promoção da empregabilidade; desenvolvimento de competências", em relação aos fornecedores, "uso de critérios transparentes (...) na escolha de fornecedores e parceiros de negócios; sempre que possível, dar preferência a fornecedores que gerem empregos e oportunidades para a economia local", (CONFEDERAÇÃO NACIONAL DA INDÚSTRIA, 2006. p. 29).

Em que pese tenha-se variados exemplares nacionais de venezuelanos expostos a trabalho análogo de escravo[6], um exemplo contundente internacionalmente noticiado e relacionado à indústria da moda foi a tragédia do Prédio Rana Plaza, em Bangladesh, em que mais de mil trabalhadores, quase a totalidade de mulheres, a serviço de fornecedores de grandes marcas internacionais morreram, revelando que além da baixíssima remuneração, as condições relacionadas à segurança eram mínimas.[7] (FRANCE PRESSE, 2013; BBC NEWS BRASIL, 2013)

De um lado grandes empresas internacionais, de outro, mulheres, subjugadas a um sistema que não thes permite nenhuma escolha e não lhes assegura nenhuma condição.

Portanto, a partir desta contextualização, importante relembrar os 10 princípios defendidos pelo Pacto Global da Organização das Nações Unidas (ONU), estabelecem as diretrizes da atuação empresarial no tocante ao $E$ e ao $S$, observandose para tanto: a) os Direitos Humanos (apoio, reconhecimento e não violação); b) os Direitos do Trabalho (liberdade de associação e a eliminação da discriminação e de todas as formas de trabalho infantil, forçado e compulsório); c) o Meio Ambiente 
(abordagem preventiva aos desafios ambientais; desenvolver e difundir novas tecnologias e promover maior responsabilidade ambiental); e d) práticas de Anticorrupção (combater a corrupção em todas as suas formas, inclusive extorsão e propina). (REDE BRASIL DO PACTO GLOBAL, s.d).

Alia-se a estes os 17 Objetivos do Desenvolvimento Sustentável (ODS) traçados pela igualmente pela Organização das Nações Unidas (ONU), em 2015, na denominada Agenda 2030, metas a serem alcançadas tanto pelo setor público, quanto setor privado e sociedade em geral para um mundo mais justo e igualitário (NAÇÕES UNIDAS BRASIL, 2015).

Diga-se de passagem, que os ODS reforçam o $E$ e o $S$, pois se constituem como "base para o fortalecimento das ações de Conduta Empresarial Responsável" que suplanta a "Responsabilidade Social Empresarial muito atrelada a ações filantrópicas e voluntárias (...) e muitas vezes dissociadas das suas próprias cadeias de fornecimento" (BRASIL, 2019. p. 9).

A implementação de todos os valores envolvidos e as metas que se quer alcançar passam com intensidade pelas empresas e é pelo $G$ (Governance) que tudo acontece.

O G, nesta toada, representa o sistema de governança corporativa adotado pela empresa, do qual partem as decisões que darão concretude a todos os parâmetros acima delineados no $E$ e no $S$, integrando-os, dirigindo-os, aplicando-os e, por consectário, usufruindo dos seus resultados.

Por governança corporativa entenda-se:

o sistema pelo qual as empresas e demais organizações são dirigidas, monitoradas e incentivadas, envolvendo os relacionamentos entre sócios, conselho de administração, diretoria, órgãos de fiscalização e controle e demais partes interessadas. (IBGC, 2017, p. 20).

A governança corporativa desenvolve-se a partir de quatro princípios: da transparência - disclosure - (disponibilização de informações de interesse das partes interessadas, além das obrigatórias por lei); da equidade - fairness - (tratamento isonômico dos sócios e demais partes interessadas, levando em consideração seus 
direitos, deveres, necessidades, expectativas); da prestação de contas ou accountability (diligência e atuação de modo claro, compreensível e tempestivo em relação às contas); e, por fim, da responsabilidade corporativa, conformidade ou compliance (viabilidade econômico financeira das empresas, reduzindo as externalidades negativas e aumentando as positivas, prognósticos e mitigação de riscos, treinamentos, códigos de conduta, com a adoção de mecanismos internos de controle). (IBGC, 2020, p. 20-21; SOUSA et al, 2021, p. 54-57).

Como visto, a empresa que adota como prática a boa governança corporativa entende seu papel no meio em que atua, está comprometida com os stakeholders e leva a sério sua política de atuação.

O compliance, neste panorama, o qual merece esclarecimentos adicionais:

deve ser tratado como um mecanismo de cumprimento de leis, normas internas e externas, de proteção contra desvios de conduta e de preservação e geração de valor econômico. (...) Em sua base, devem estar os princípios básicos de governança corporativa". (IBGC, 2017, p. 11)

Em que pese a ideia original remonte à "Lei Americana Foreing Corrupt Practices Act, mais conhecida como FCPA" a qual teve "como motor propulsor a necessidade de não se punir a corrupção apenas dentro do Estado norte americano, mas também no exterior" (TEIXEIRA, KASEMIRSKI, 2021, p.23), ao se falar em compliance, "não se deve ter em mente que este se refere tão somente a questões anticorrupção, uma vez que, em áreas que envolvam relações entre fornecedor e consumidor, assim como o meio ambiente, torna-se relevante." (SEGAL, 2018).

É pelo compliance efetivo e aferido, portanto, que se garantirá que a empresa esteja alinhada com o ESG, no sentido de realizar tudo que Ihe é de fundamental importância a fim de permitir o cumprimento do seu propósito de existir para além do lucro, porque mais do que "estar em compliance" o que se propõe e se evidencia pelo ESG é o "ser compliant" num processo de engajamento institucional que começa justamente pela governança, afinal é importante que "o tom que vem do topo" comprometa-se alinhar o seu discurso à sua ação. (IBGC, 2017, p. 13-14). 
Por fim, encerra-se este artigo com a advertência que o ESG não é algo a ser incorporado apenas pelas grandes corporações, não só porque muitas destas já exigem de seus fornecedores menores igual adequação e atendimento às premissas que sustentam o ESG, mas, sobretudo, porque o mercado de consumo, na mesma ótica de tudo que fora exposto no capítulo anterior, é igualmente aplicável às pequenas e médias empresas; seja porque fortalece o seu valor expandindo suas relações negociais; seja porque a elas se abrem linhas de crédito especiais para negócios sustentáveis[8]; seja porque se alinham qualitativamente para receber investimentos voltados a sustentabilidade, entre outros fatores (ROLLI, 2021), mas principalmente porque, por enquanto, não é tarde demais para todos fazer a coisa certa.

\section{CONCLUSÃO}

A partir do ideário da liberdade, o indivíduo foi reconhecido e o direito à propriedade Ihe foi garantido como um consectário, mas percebendo que apenas encontra justificativa da sua existência em sociedade, exsurgiu o bem comum como a temática a ser perseguida.

Nesta perspectiva, o que é bom para si deve ser, em igual medida, bom aos demais, na vida privada, no trabalho, no meio ambiente, em todas as vertentes das relações humanas.

À empresa, como resultado da conjugação de esforços e da própria constatação da existência em sociedade, imputa-se igual missão de atender a deveres éticos socioambientais, os quais sobrepujam a sua existência.

$\mathrm{Na}$ atualidade, as empresas que compreendem e implementam as diretrizes ESG, termo sugerido no Relatório Who Cares Wins emitido no contexto do Pacto Global, da Organização da Nações Unidas (ONU), em 2004, demonstram-se adaptadas às exigências deste século, alinhando-se a um propósito de existência para além do lucro, pois desenvolvem suas atividades empresariais a partir de decisões éticas 
integradas pelas questões ambientais e sociais, num ambiente de governança corporativa comprometido.

Nesta conjuntura as empresas compreendem a sua influência e a sua força nas dinâmicas da vida, assumem a sua parcela de responsabilidade socioambiental, externalizam impactos positivos e se esforçam para minimizar os negativos, percebem, como decorrência desta gestão eficiente e humanitariamente conectada, tanto os benefícios econômicos, quanto a geração e a manutenção do seu valor de forma longeva, contribuindo, ao final, com a construção de um mundo melhor.

\section{REFERÊNCIAS}

AMADO. Frederico. Direito ambiental. 5ª .ed. Salvador: JusPodivm, 2017.

BATALHA, M. A. R. Gestão Ambiental e Sustentabilidade: uma nova realidade empresarial. Revista Científica Intr@ciência, v. 01, p. 22-29, 2013. Disponível em: $<$ http://uniesp.edu.br/sites/_biblioteca/revistas/20170531141914.pdf>. Acesso em 12/08/2021.

BARACHO, Hertha Urquiza; CECATO, Maria Aurea Baroni. Da função social da empresa à responsabilidade social: reflexos na comunidade e no meio ambiente. Direito e Desenvolvimento. V.7. n.2. p. 114-128. João Pessoa, 2017. Disponível

em:

$<$ https://periodicos.unipe.br/index.php/direitoedesenvolvimento/article/view/320/300>. Acesso em: 27/05/2021.

BBC NEWS BRASIL. Desabamento em Bangladesh revela lado obscuro da indústria de roupas. 28/04/2013. Disponível em: https://www.bbc.com/portuguese/noticias/2013/04/130428_bangladesh_tragedia_lad o_obscuro>. Acesso em: 07/10/2021.

BERNARDES, Juliano Taveira; FERREIRA, Olavo Augusto Vianna Alves. Direito Constitucional. Tomo II - Direito Constitucional Positivo. 7a․ ed. Salvador: JusPodivm, 2018. 
BORGER, Fernanda Gabriela. Responsabilidade social empresarial e sustentabilidade para a gestão empresarial. São Paulo: Instituto Ethos, 2013. Disponível em: <https://www.ethos.org.br/cedoc/responsabilidade-social-empresariale-sustentabilidade-para-a-gestao-empresarial/>. Acesso em 29/09/2021.

B3 BRASIL BOLSA BALCÃO. Sustentabilidade nas empresas: como começar, quem envolver e o que priorizar. 2ª ed. 2016. Disponível em: $<$ http://www.b3.com.br/pt_br/b3/sustentabilidade/produtos-e-servicos-esg/guias-epublicacoes/.> Acesso em: 31/05/2021.

BRASIL. Constituição da República Federativa do Brasil de 1988, de 5 de outubro de $1988 . \quad$ Disponível em: <http://www.planalto.gov.br/ccivil_03/constituicao/constituicao.htm>. Acesso em: 05/10/2021.

. Emenda Constitucional ํㅜ 1, de 17 de outubro de 1969. Edita o novo texto da Constituição Federal de 24 de janeiro de 1967. Diário Oficial da União, DF, de 20/10/1969.

Disponível

em: <http://www.planalto.gov.br/ccivil_03/constituicao/emendas/emc_anterior1988/emc01 -69.htm>. Acesso em: 05/10/2021.

. Lei n. 6.404, 15 de dezembro de 1976. Dispõe sobre as Sociedades por Ações. Diário Oficial da União, Brasília, DF, 17 dez. 1976. Disponível em: <http://www.planalto.gov.br/ccivil_03/Leis/L6404consol.htm> Acesso em: 07/06/2021.

. Lei no 10.406, de 10 de janeiro de 2002. Institui o Código Civil. Diário Oficial da União: Brasília, DF, 11 jan. 2002. Disponível em: <http://www.planalto.gov.br/ccivil_03/leis/2002//10406compilada.htm>. Acesso em: 08/10/2021.

Princípios Orientadores para Empresas e Direitos Humanos. Brasília: Ministério da Mulher, da Família e dos Direitos Humanos, 2019. Disponível em: $<$ https://www.gov.br/mdh/pt- 
br/assuntos/noticias/2019/outubro/Cartilha_versoimpresso.pdf>

Acesso

em: 18/08/2021.

COELHO, Fábio Ulhoa. Princípios constitucionais na Interpretação das normas de direito comercial. In SALOMÃO, Luis Felipe; CUEVA, Ricardo Villas Bôas; FRAZÃO, Ana. (Coords). Lei de liberdade econômica e seus impactos no direito brasileiro. 1ª. ed. São Paulo: Thomson Reuters Brasil, 2020. p. 431-450. Vários autores.

CONFEDERAÇÃO NACIONAL DA INDÚSTRIA. Responsabilidade social empresarial. Brasília: CNI, 2006. Disponível em: $<$ http://www.portaldaindustria.com.br/publicacoes/2012/9/responsabilidade-socialempresarial/>. Acesso em: 07/08/2021.

COLINS, Jim. Empresas feitas para vencer. Rio de Janeiro: Alta Books, 2018.

COMPARATO, Fábio Konder. Estado, empresa e função social. RT/Fasc. Civil. Revista dos Tribunais, São Paulo. ano.85. v.732. out. 1996. p.39-46. Disponível em: <https://edisciplinas.usp.br/pluginfile.php/238790/mod_resource/content/1/Estado\%2 C\%20Empresa\%20e\%20Fun\%C3\%A7\%C3\%A30\%20Social\%20\%20F\%C3\%A1bio\%20Konder\%20Comparato.pdf>. Acesso em: 12/08/2021.

CORREA, María Emília. Sistema B e as Empresas B na América Latina: Um movimento social que muda o sentido do sucesso empresarial. Tradução de Julia Nemirowsky e Latinlingua. CAF Banco do Desenvolvimento da América Latina: Colômbia, 2019. Disponível em: <https://scioteca.caf.com/handle/123456789/1716>. Acesso em: 02/08/2021.

CRUZ, André Santa. Direito Empresarial. 11ª .ed Salvador: JusPodivm, 2021.

FARIAS, Cristiano Chaves de; ROSENVALD, Nelson. Curso de direito civil: direitos reais. vol.5 14ㄹ. ed. rev.amp. e atual. Salvador: JusPodivm, 2018.

FRANCE PRESSE. Bangladesh pede prisões por queda de prédio com mil mortos em 2013. G1 21 dez.2015. Disponível em: 
<http://g1.globo.com/mundo/noticia/2015/12/bangladesh-pede-prisoes-por-queda-depredio-com-mil-mortos-em-2013.html>. Acesso em: 05/10/2021.

FRAZÃO, Ana. Liberdade Econômica Para Quem? A Necessária Vinculação Entre a Liberdade de Iniciativa e a Justiça Social. In SALOMÃO, Luis Felipe; CUEVA, Ricardo Villas Bôas; FRAZÃO, Ana. (Coords). Lei de liberdade econômica e seus impactos no direito brasileiro. 1‥ ed. São Paulo: Thomson Reuters Brasil, 2020. p. 89-121. Vários autores.

FUNDAÇÃO GETÚLIO VARGAS. Webinar Conecta FGV:ESG - ambiente Presente e Futuro: o que é possível, desejável e urgente? 30/06/2021. Disponível em: <https://www.youtube.com/watch?v=W-QRFSDZA04\&t=2964s>. Acesso em: 05/10/2021.

GARCIA. Neves Garcia et al. Inovação no Comportamento do Consumidor: Recompensa às Empresas Socioambientalmente Responsáveis. In RAI - Revista de Administração e Inovação, vol. 5, núm. 2, 2008, pp. 73-91 Universidade de São Paulo: 2008. Disponível em: $<$ https://www.redalyc.org/pdf/973/97317204006.pdf>.Acesso em 13/08/2021.

GLOBAL REPORTING INICIATIVE (GRI). A ASG como estratégia da perenidade dos negócios no séc. $\mathrm{XXI}$ : perspectivas de profissionais de sustentabilidade e de conselhos de administração. São Paulo: IBGC, 2019. Disponível em: $<$ <ttps://conhecimento.ibgc.org.br/Paginas/Publicacao.aspx?Publd=24136>. Acesso em: 05/10/2021.

GUIMARÃES, Solange. Revolução ESG inaugura nova fase do capitalismo. In Forbes 14/08/2021. Disponível em: <https://forbes.com.br/forbesesg/2021/08/revolucao-esginaugura-nova-fase-do-capitalismo/>. Acesso em: 07/10/2021.

HART, Stuart L.; MILSTEIN Mark B. Criando Valor Sustentável. In R.A.E Executivo. Especial A.M.E. v.3.n 2. 2004. maio-julho. Disponível em: <https://bibliotecadigital.fgv.br/ojs/index.php/gvexecutivo/article/view/34820/33619>. Acesso em: 13/08/2021. 
IBGC - INSTITUTO BRASILEIRO DE GOVERNANÇA CORPORATIVA. Compliance à luz da gestão corporativa. 1ª̣. ed. São Paulo: IBGC, 2017. Disponível em: $<$ https://conhecimento.ibgc.org.br/Paginas/Publicacao.aspx?Publd=23486>. Acesso em: 01/06/2021.

. Guia de Sustentabilidade para as Empresa. BRANDÃO, Carlos Eduardo Lessa; SANTOS, Homero Luís (coords). São Paulo: IBGC, 2007. Disponível <https://conhecimento.ibgc.org.br/Lists/Publicacoes/Attachments/22127/Caderno_4_ Guia_Sustentabilidade_Empresas.pdf $>$. Acesso em: 05/10/2021.

Governança é a chave do ESG no mundo. In Blog do IBGC. São Paulo, 2020. Disponível em: <https://www.ibgc.org.br/blog/governanca-esg-no-mundo>. Acesso em 05/10/2021.

. Código das Melhores Práticas de Governança Corporativa. $5^{a}$.ed. São Paulo: IBGC, $2015 . \quad$ Disponível em: <https://conhecimento.ibgc.org.br/Paginas/Publicacao.aspx?Publd=21138>

IEDI - INSTITUTO DE ESTUDOS PARA O DESENVOLVIMENTO INDUSTRIAL. A Posição do Brasil na Transição Verde Mundial. São Paulo: abril/2021. Disponível em:

$<$ https://iedi.org.br/artigos/top/estudos_comercio/20210422_trans_verde.html>.Acess o em: 13/10/2021.

INSTITUTO ETHOS. Práticas empresariais de responsabilidade social: Relação entre os princípios do Global Compact e os Indicadores Ethos de Responsabilidade Social Empresarial. Carmen Weingrill. coord. São Paulo: Instituto Ethos, 2003. Disponível em: <https://www.ethos.org.br/wpcontent/uploads/2012/12/18.pdf.> Acesso em: 31/05/2021.

INTERNACIONAL FINANCE CORPORATION. Who Cares Wins - Connecting Financial Markets to a Changing World. jun/2004. Disponível em: $<$ https://www.ifc.org/wps/wcm/connect/topics_ext_content/ifc_external_corporate_sit e/sustainability-at- 
ifc/publications/publications_report_whocareswins wci 1319579355342>. Acesso em 05/10/2021.

LEGAL ETHICS COMPLIANCE. ESG e Compliance - Qual a Relação? In Blog do LEC. 06/2021. Disponível em: <https://lec.com.br/beta2021/esg-e-compliance-quala-relacao/>. Acesso em: 08/08/2021.

LENZA, Pedro. Direito Constitucional Esquematizado. 19ª ed. São Paulo: Saraiva, 2015.

LIMA; Marcos da Silva; RIBEIRO, Fernando Bessa. Capitalismo consciente: Uma configuração mais justa ou a arte de se reinventar para continuar a existir? In Revista da Associação Portuguesa de Sociologia, n. -22 - abril 2020. Disponível em: $<$ https://revista.aps.pt/pt/capitalismo-consciente-uma-configuracao-mais-justa-ou-aarte-de-se-reinventar-para-continuar-a-existir/>. Acesso em 03/08/2021.

MINISTÉRIO PÚBLICO FEDERAL. Caso Samarco. O desastre. Disponível em: <http://www.mpf.mp.br/grandes-casos/caso-samarco/o-desastre>. Acesso em 06/10/2021.

MORSCH, Marco Aurelio. Modismo ou imperativo de negócios? 15/04/2021. Disponível em: <https://administradores.com.br/artigos/esg-modismo-ou-imperativopara-os-neg\%C3\%B3cios>. Acesso em: 13/08/2021.

NAÇÕES UNIDAS NO BRASIL. A ONU e o Meio Ambiente. Brasília, 2020. Disponível em: <https://brasil.un.org/pt-br/91223-onu-e-o-meio-ambiente>. Acesso em: 13/08/2021.

Transformando Nosso Mundo: A Agenda 2030 para o Desenvolvimento Sustentável. 15/09/2015. Disponível em: <https://brasil.un.org/ptbr/91863-agenda-2030-para-o-desenvolvimento-sustentavel>. Acesso em 07/10/2021. 
NAKAGAWA, Marcus. ESG ou Sustentabilidade Empresarial? Redação NS. In Notícia Sustentável. Salvador, 2020. Disponível em: $<$ https://www.noticiasustentavel.com.br/artigo-esg-sustentabilidade-empresarial/>. Acesso em: 09/08/2021.

NETO, Dario; FUKAYAMA, Marcel. O quinto pilar. In Blog Capitalismo Consciente Brasil. São Paulo, 2021. Disponível em: <https://www.ccbrasil.cc/post/o-quinto-pilar>. Acesso em: 03/08/2021.

NOVELINO, Marcelo. Curso de direito constitucional. 12ª ${ }^{a}$ ed.rev.,ampl.e atual. Salvador: JusPodivm, 2017.

PEREIRA, CARLO. ESG é uma preocupação que está tirando o seu sono? In Blog da Exame Invest. 0/10/2020. Disponível em: <https://exame.com/blog/carlopereira/esg-o-que-e-como-adotar-e-qual-e-a-relacao-com-asustentabilidade/>. Acesso em: 03/08/2021.

PEREIRA, Flávio de Leão; RODRIGUES, Rodrigo Bordalo. Compliance em Direitos Humanos, Diversidade e Ambiental. Coleção Compliance. vol. VI. NOHARA, Irene Patrícia Diom; ALMEIDA, Luiz Eduardo de. (coords). São Paulo: Thomson Reuters Brasil, 2021.

RAMOS, Cesar Augusto. Aristóteles e o sentido político da comunidade ante o liberalismo. In Revista Kriterion da Universidade Federal de Minas Gerais. n. 129. jun/2014. p. 61-77. Belo Horizonte, 2014. Disponível em: $<$ https://www.scielo.br/j/kr/a/XjTrB66wvsrMgSD8RN4kXVD/?lang=pt>. Acesso em 14/09/2021.

REDE BRASIL DO PACTO GLOBAL. ESG. Entenda o significado da sigla ESG (Ambiental, Social e Governança) e saiba como inserir esses princípios no dia a dia de sua empresa. Disponível em: $<$ https://www.pactoglobal.org.br/pg/esg?gclid=CjwKCAjwsNilBhBdEiwAJK4khvK4dZ K7cEVN5XC-_N3-rvkGRzop2sV9vwqSA7yA0UQ2oJZXW_UebxoC47kQAvD_BwE> Acesso em 09/08/2021. 
Os 10 princípios. <https://www.pactoglobal.org.br/10principios>. Acesso em: 07/10/2021.

REDE BRASIL DO PACTO GLOBAL; STILINGUE. A Evolução do ESG no Brasil. 2021. Disponível em: <https://conteudos.stilingue.com.br/estudo-a-evolucao-do-esgno-brasil>. Acesso em 13/08/2021.

REDECKER, Ana Cláudia; TRINDADE, Luiza de Medeiros. Práticas de ESG em sociedades anônimas de capital aberto: um diálogo entre a função social instituída pela Lei 6.404/1976 e a geração de valor. In Revista Jurídica LusoBrasileira, Ano 7, 2021, n. 2, 50-125. Disponível em: <https://www.cidp.pt/revistas/rjlb/2021/2/2021_02_0059_0125.pdf>.Acesso em: 03/08/2021.

RIOS, Terezinha Azerêdo. A presença da filosofia e da ética no contexto profissional. In Revista Brasileira de Comunicação Organizacional e Relações Públicas. Departamento de Relações públicas, Propaganda e Turismo, Escola de Comunicações e Artes, Universidade de São Paulo. Ano 5. Número 8. 1ำ semestre. São Paulo: USP, 2008. p. 78-88. Disponível em: $<$ https://www.revistas.usp.br/organicom/article/view/138969>. Acesso em 01 jun.2021.

ROLLI, Claudia. Ações sustentáveis definirão futuro de pequenas empresas. In Folha de São Paulo. 21/05/2021. Disponível: <https://www1.folha.uol.com.br/mpme/2021/05/acoes-sustentaveis-definirao-futurode-pequenas-empresas.shtml>. Acesso em 07/10/2021.

SCABIN, Flávia; ACCA, Thiago dos Santos. Implementando os princípios orientadores sobre empresas e direitos humanos da ONU: o dever do Estado de proteger e a obrigação das empresas de respeitar os direitos humanos. 2017. Disponível em: <https://bibliotecadigital.fgv.br/dspace/handle/10438/28697:>. Acesso em: 21 set.2021. 
SMITH, Manoella. Pandemia ajudou a impulsionar adesão a conceitos de ESG, dizem debatedores. Adoção de boas práticas ambientais, sociais e de governança marca mudança de paradigma. Folha de São Paulo, 29/05/2021. Disponível em: <https://www1.folha.uol.com.br/seminariosfolha/2021/05/pandemia-ajudou-aimpulsionar-adesao-a-conceitos-de-esg-dizem-debatedores.shtml>. Acesso em: 05/10/2021.

SOUSA, Henrique Adriano de et al. Os Princípios da Governança Corporativa: Os Enfoques dados pelas Empresas Listadas na B3. In Revista Contabilidade e Controladoria, Curitiba, v. 13, n. 1, p. 50-71, jan./abr. 2021. Disponível em: < https://revistas.ufpr.br/rcc/article/view/75295/43426>. Acesso em: 13/08/2021.

TAVARES, André Ramos. Curso de Direito Constitucional. São Paulo: Saraiva, 2002.

TEIXEIRA, Tarcísio; KASEMIRSK, André Pedroso. Compliance (conformidade) de dados pessoais para microempresas: autorregulação regulada e requisitos para efetividade. In Empresas e implementação da LGPD. TEIXEIRA, Tarcisio (coord). Salvador: Editora JusPodivm, 2021. p.17-50. Vários autores.

WEBER, Mariana. Especial ESG: Natura \&Co. In Forbes. 22/08/2021. Disponível em: <https://forbes.com.br/forbesesg/2021/08/especial-esg-natura-co/>. Acesso em 06/10/2021.

\section{APÊNDICE - REFERÊNCIA NOTA DE RODAPÉ}

2. "O lema da Revolução Francesa (Liberté, Egalité, Fraternité), invocado há 200 anos, parece que ainda não se implementou totalmente". (TAVARES, 2002, p. 375).

3. "O desenvolvimento que encontra as necessidades atuais sem comprometer a habilidade das futuras gerações de atender suas próprias necessidades" (ONU, 2020)

4. A doutrina mais atual prefere empregar o termo "dimensões" ao revés de "gerações", por entender que uma nova dimensão não abandona a anterior. Partindo 
do lema da Revolução Francesa - liberdade, igualdade e fraternidade, tem-se as 1"a $2^{\mathrm{a}}$ e $3^{\mathrm{a}}$ dimensão. (LENZA, 2015, p. 1144).

5. Texto original: "The institutions endorsing this report are convinced that in amore globalised, interconnected and competitive world the waythat environmental, social and corporate governance issues aremanaged is part of companies' overall management quality need-ed to compete successfully." (INTERNACIONAL FINANCE CORPORATION, 2004, p. 5)

6.

$<$ https://g1.globo.com/ba/bahia/noticia/2019/04/18/venezuelanos-em-situacaoanaloga-ao-trabalho-escravo-sao-resgatados-no-sul-da-bahia-dois-homens-saopresos.ghtml>; <https://amazonasatual.com.br/familia-venezuelana-e-explorada-emoficina-de-costura-no-brasil/>; <https://brasil.elpais.com/brasil/2021-05-17/ambev-eheineken-sao-autuadas-por-trabalho-escravo-de-imigrantes-venezuelanos-em-saopaulo.html>. Acesso em 07/10/2021.

7. O documentário The True Coast, produzido em 2015, dirigido por Andrew Morgan, expõe a temática.

8. Confira-se a título de exemplo os "Financiamentos Socioambientais" disponíveis pelo Banco Santander para empresas com projetos que primam pela sustentabilidade.

$<$ https://www.santander.com.br/sustentabilidade/negocios-socioambientais/para-suaempresa>. Acesso em 07/10/2021.

Enviado: Setembro, 2021.

Aprovado: Dezembro, 2021. 